\title{
RESULTADOS DO USO DE REA EM CURSO SOBRE INCLUSÃO DA PESSOA COM DEFICIÊNCIA
}

\author{
SÃO PAULO/SP JULHO/2018 \\ Edison Trombeta de Oliveira
Nadia Rubio Pirillo
}

Tipo: Relato de Experiência Inovadora (EI)

Categoria: Métodos e Tecnologias

Setor Educacional: EDUCAÇÃO SUPERIOR, EDUCAÇÃO CONTINUADA EM GERAL

\begin{abstract}
RESUMO
Em 2017, foi ofertado o curso "Direitos da Pessoa com Deficiência: Diversidade Humana e Igualdade", pela Universidade Virtual do Estado de São Paulo (UNIVESP) em parceria com a Secretaria de Estado dos Direitos da Pessoa com Deficiência. Uma das atividades iniciais da formação foi um Recurso Educacional Aberto (REA), que visava auxiliar no diagnóstico do modelo de pensamento do aluno sobre a deficiência (caritativo, médico ou social). Este artigo visa relatar o processo de produção desse REA, desenvolvido utilizando técnicas e processos específicos, bem como o produto final, que materializa os princípios da instituição e funcionalidades de acessibilidade. Como resultados, destacam-se as mídias e os dispositivos utilizados para acesso ao recurso educacional, que evidenciam a necessidade de se pensar em responsividade, acessibilidade $e$ possibilidades de compartilhamento na criação de REA.
\end{abstract}

Palavras-chave: Educação a distância; Ensino Superior; Recurso Educacional Aberto; Inclusão; Acessibilidade. 


\section{Introdução}

Conhecimento como bem público e uso intensivo de tecnologias são princípios que sustentam a visão de educação da Universidade Virtual do Estado de São Paulo (UNIVESP). Criada em 2012 como Fundação, a UNIVESP oferece cursos de graduação (Licenciaturas, Engenharias e Tecnólogo), pós-graduação e cursos livres.

Um dos cursos da UNIVESP é o "Direitos da Pessoa com Deficiência: Diversidade Humana e Igualdade", ofertado a distância em parceria com a Secretaria de Estado dos Direitos da Pessoa com Deficiência. Foram atendidos 4 mil inscritos, em quatro turmas, entre julho e outubro de 2017. O objetivo geral foi sensibilizar os agentes públicos para o comprometimento, no desempenho das suas atividades, respeitando a diversidade.

O curso contém cinco módulos de estudo, além da ambientação: O que é deficiência: história e modelos; Os direitos humanos e as pessoas com deficiência; Acessibilidade e tecnologias assistivas; Cidadania e bem-estar social: educação, saúde e reabilitação; Cidadania e bem-estar social: cultura e trabalho. A carga horária do curso é de 30 horas, divididas entre vídeos, leituras e questionários avaliativos. A UNIVESP desenvolveu três Recursos Educacionais Abertos (REA) para o curso: Conecte a ti mesmo, Qual é o meu pensamento sobre a deficiência? e Jogo dos cinco acertos do desenho universal".

Figura 1. Recurso Educacional Aberto "Qual é o meu pensamento sobre a deficiência"

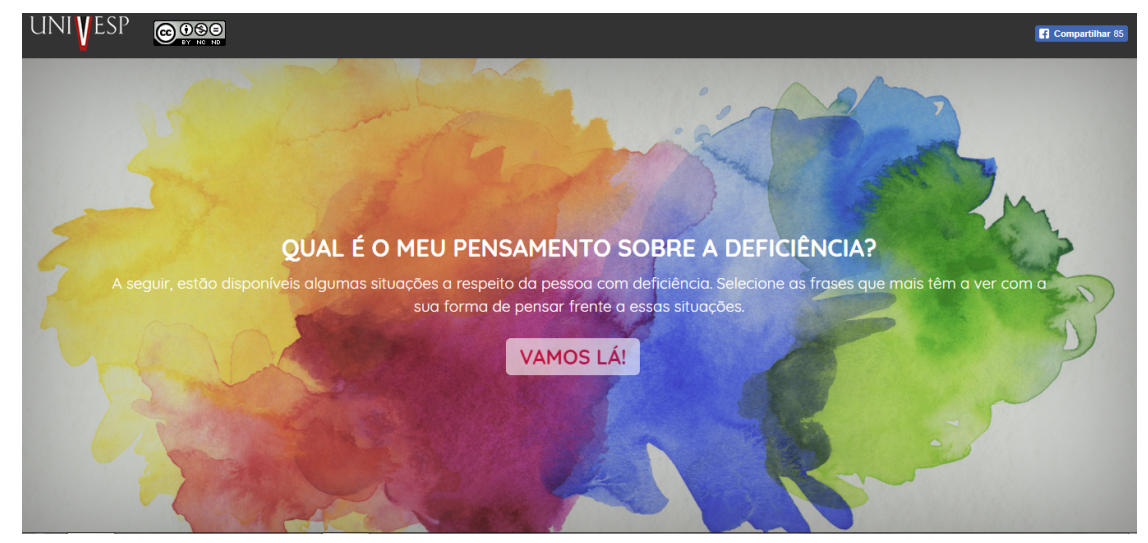

Fonte: https://apps.univesp.br/qual-e-o-meu-pensamento-sobre-a-deficiencia/

Neste trabalho, considera-se que REA seja um recurso de acesso aberto utilizado para fins educacionais, ou seja, disponibilizado por licenças abertas, como a Creative Commons (CC), que permitem diferentes cenários de uso e cocriação (PRETTO, 2012).

O foco do presente trabalho está no REA "Qual é o meu pensamento sobre a deficiência?", cujo objetivo é auxiliar no diagnóstico do modelo de pensamento sobre a 
deficiência (caritativo, médico ou social). O REA foi utilizado em dois momentos: no início (diagnóstico) e ao fim, buscando averiguar se o pensamento sobre a deficiência dos alunos havia se alterado no decorrer do curso.

O objetivo deste artigo é relatar o processo de produção desse REA, construído sob os princípios da instituição e com acessibilidade, bem como o produto final e os resultados quantitativos do seu uso. Para tanto, será relatada a experiência da produção do REA e serão utilizados os dados de acesso relativos à primeira turma.

\section{Metodologia}

Uma vez que este trabalho é um relato de experiência, aponta-se seu caráter qualiquantitativo. Neste contexto, o presente artigo é de cunho descritivo, pois observa, registra, analisa, classifica e interpreta os dados a fim de identificar as relações entre as variáveis propostas. Parte-se de uma pesquisa bibliográfica, ponto inicial para seleção e delimitação do tema, localização e coleta das informações, etc (ANDRADE, 2010).

A partir dessas premissas, houve descrição e análise do processo de produção do REA e do produto final. Na sequência, foram analisados e discutidos dados de uso, obtidos por meio do Google Analytics, um serviço gratuito para exibição de estatísticas de acesso e uso de produtos digitais. As principais informações coletadas são sobre como o público acessou o recurso, como as datas de maior utilização, quais as formas de acesso mais comuns e quais dispositivos mais usados.

\section{O processo de produção do REA}

Os REAs devem ter uma intencionalidade pedagógica, despertando a atenção e propiciando oportunidades de aprendizagem aos estudantes. Pensando nisso, o processo de criação dos REAs na UNIVESP se apoia em três técnicas principais: brainstorming, metáfora e prototipação, amplamente definidas em Gara et al (2016).

Brevemente, o brainstorming é o momento de colocar as necessidades e as ideias em discussão, de forma a selecionar aquelas que possam atender às demandas educacionais específicas do recurso que será produzido. Três foram os modelos apresentados no curso: modelo caritativo, aquele no qual a pessoa com deficiência é vista como incapaz e cuja deficiência deve ser encarada com piedade; modelo médico, no qual a pessoa com deficiência precisa ser curada; modelo social, para o qual a sociedade deve assegurar que as pessoas com deficiência tenham os seus direitos garantidos e respeitados. 
Após estas definições iniciais, a produção do REA passa para a etapa da metáfora, que contribui para a articulação entre pedagogia e estética a fim de estabelecer relação entre a teoria e prática.O universo representacional escolhido foi o de situações cotidianas que envolvessem pessoas com diferentes tipos de deficiência (visual, auditiva, física e intelectual).

Para cada situação, eram fornecidos três comentários, representando cada um dos modelos de pensamento sobre a deficiência. Por exemplo: a partir da situação "Mãe conversando com a filha surda em Libras", as alternativas eram: "Deve haver uma operação ou um aparelho auditivo que vai ajudar essa menina"; "Deve ser muito difícil ter uma filha surda que sempre vai precisar de ajuda"; "Queria saber como elas se comunicam tão bem".

No topo do REA, foi inserido um círculo que ganha determinadas cores de acordo com cada resposta dada pelo aluno: respostas relacionadas ao modelo caritativo ganham a cor vermelha; ao modelo médico, cor verde; e ao modelo social, a cor é azul. Caso todas as respostas sejam de um mesmo modelo, a cor permanece pura; caso haja diversidade nas respostas, as cores vão se misturando.

Figura 2. Situação cotidiana representada no REA "Qual é o meu pensamento sobre a deficiência"

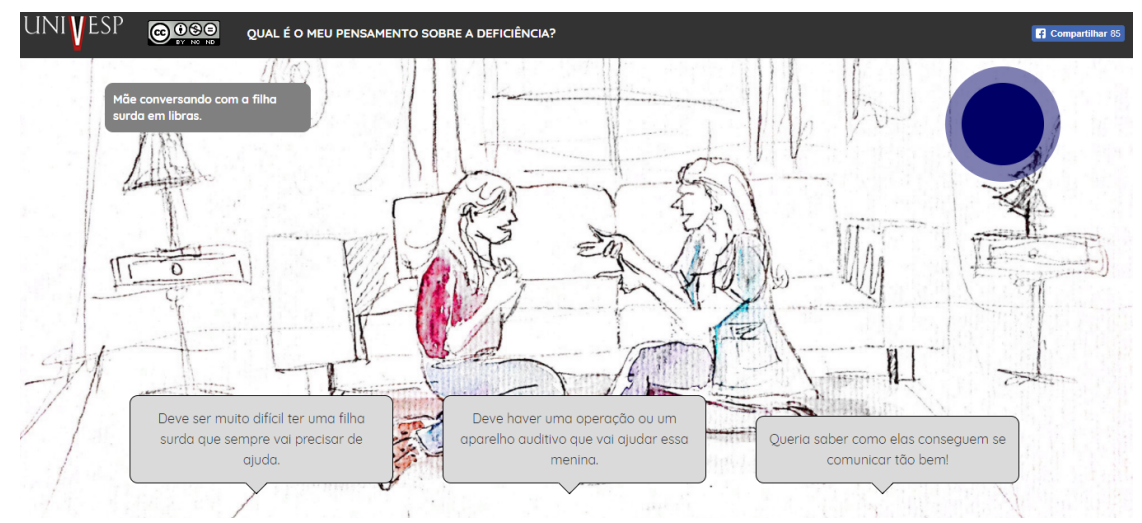

Fonte: https://apps.univesp.br/qual-e-o-meu-pensamento-sobre-a-deficiencia/

Por fim, processo de produção do REA chega à prototipação, quando se materializa a ideia, inclusive para auxiliar nas validações do material.

Para as equipes envolvidas na produção do recurso, essa é uma fase útil para visualizar o funcionamento do REA e fazer as correções que forem necessárias. Esse foi o momento em que as situações cotidianas foram ilustradas, as interações com as cores 
foram aplicadas e testes mínimos de acessibilidade foram realizados.

\section{O produto final}

O REA "Qual o meu pensamento sobre a deficiência" apresentou, no total, cinco situações cotidianas envolvendo as pessoas com deficiência: uma delas era sobre uma moça em cadeiras de rodas tentando subir numa calçada; a outra sobre uma criança com deficiência intelectual chegando na escola levada pela família; a seguinte sobre uma mãe conversando com a filha surda em Libras; a seguinte sobre uma mulher cega andando pelas ruas de uma cidade com cão-guia; e, por fim, a situação onde pessoas sem deficiência estão com uma pessoa com deficiência física e seu acompanhante numa piscina.

Para cada um dessas situações, foram colocados três comentários. Cada um deles se aproximava de um modelo de pensamento sobre a deficiência. Conforme o comentário é escolhido, a cor associada a ele se mistura no topo da tela.

Ao final das cinco situações, a cor gerada é apresentada, assim como o resultado obtido de acordo com cada um dos modelos de pensamento.

Figura 3. Resultado exibido no REA "Qual é o meu pensamento sobre a deficiência"

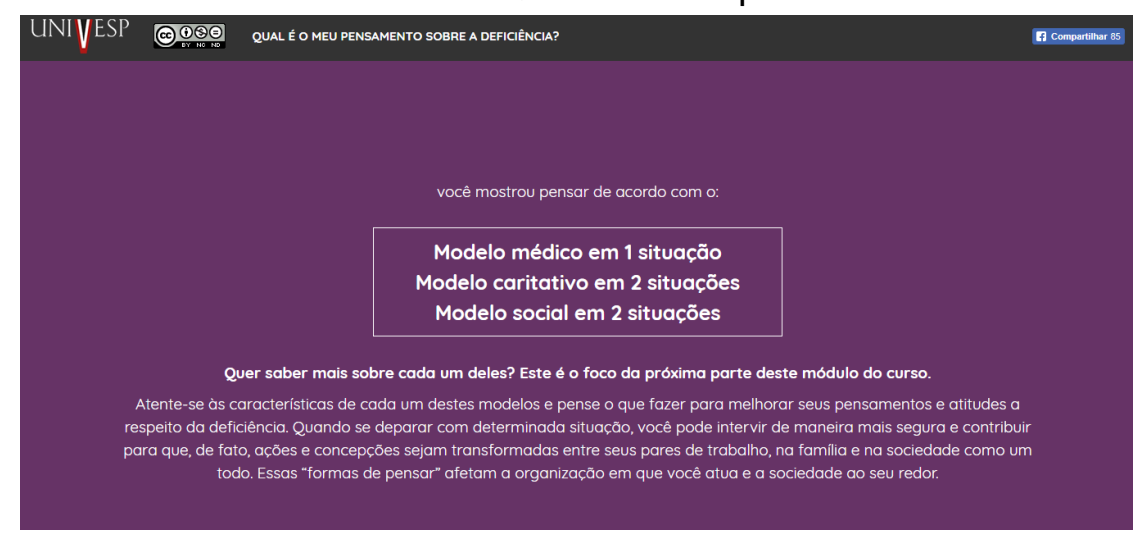

Fonte: https://apps.univesp.br/qual-e-o-meu-pensamento-sobre-a-deficiencia/

Com base no conhecimento como bem público, um dos princípios da UNIVESP, e considerando que o recurso educacional deveria ser "aberto", o REA "Qual o meu pensamento sobre a deficiência" leva a licença Creative Commons (CC).

O selo CC aplicado ao recurso permite que ele seja compartilhado e utilizado em outros contextos educacionais, desde que atribuídos os créditos autorais. 
Além da licença, foi disponibilizada também a ferramenta de compartilhamento no Facebook, de forma que o REA possa alcançar outras pessoas, além dos matriculados no curso.

Figura 4. Ferramenta de compartilhamento do REA

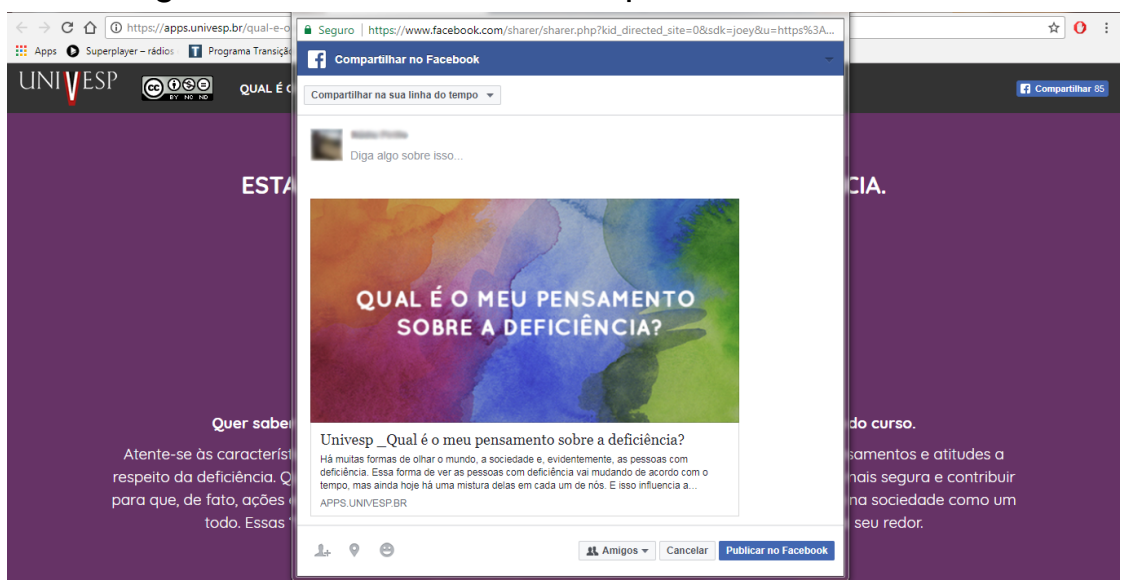

Fonte: https://apps.univesp.br/qual-e-o-meu-pensamento-sobre-a-deficiencia/

Para que o REA tivesse recursos de acessibilidade, foram colocadas em prática duas iniciativas: audiodescrição e navegação simplificada. De acordo com Leal Ferreira e Nunes (2008), a audição e o tato são os principais meios de acesso às informações para as pessoas com deficiência visual, no entanto elas possuem grande dificuldade para uso do mouse no acesso a conteúdos (OLIVEIRA et al, 2016).

Por isso, as pessoas com deficiência utilizam frequentemente os atalhos do teclado para navegação. Sobre a audiodescrição, destaca-se que seu objetivo principal é tornar os materiais que possuem elementos visuais acessíveis a pessoas com deficiência visual. Assim, "consiste na transformação de imagens em palavras para que as informaçõeschave transmitidas visualmente não passem despercebidas e possam também ser acessadas por pessoas cegas ou com baixa visão" (FRANCO; SILVA, 2010, p. 23).

Dentro do curso "Direitos da Pessoa com Deficiência: Diversidade Humana e Igualdade", o REA "Qual o meu pensamento sobre a deficiência" foi utilizado em dois momentos: no primeiro e no último módulos.

A intenção em aplicar o recurso educacional em dois momentos era fazer com que os alunos percebessem seu modelo de pensamento sobre a deficiência antes e depois da formação. Era importante também que esses resultados fossem analisados e compartilhados entre os alunos. 
Para tanto, no último módulo do curso foi inserido o fórum "Reconsiderando os modelos de pensamento", no qual os alunos foram convidados a apresentar e discutir seus modelos de pensamento com os colegas.

Os resultados quantitativos do uso desse recurso, tanto dentro do fórum proposto na primeira turma ofertada, quanto os dados obtidos por meio do Google Analytics, são apresentados a seguir.

\section{Resultados quantitativos do uso do REA}

O fórum "Reconsiderando os modelos de pensamento" teve um total de 81 postagens. Como já mencionado, esse fórum aconteceu no último módulo do curso e pedia para o aluno acessar novamente o recurso educacional para que, assim, pudesse comparar os resultados obtidos nesse momento final da formação com aquele que havia obtido no início do curso. O gráfico com a quantidade diária de acesso é apresentado na Figura 5.

Esses dados mostram que os picos de visita à página ocorreram no início de julho, quando os alunos estavam no início do curso e em meados de agosto, quando o curso já estava sendo finalizado para a primeira turma. Isso evidencia que os alunos, retornaram ao recurso e refizeram seus testes, atendendo a uma das propostas desse curso que era a autopercepção crítica em relação às pessoas com deficiência.

Figura 5. Visão geral do público-alvo

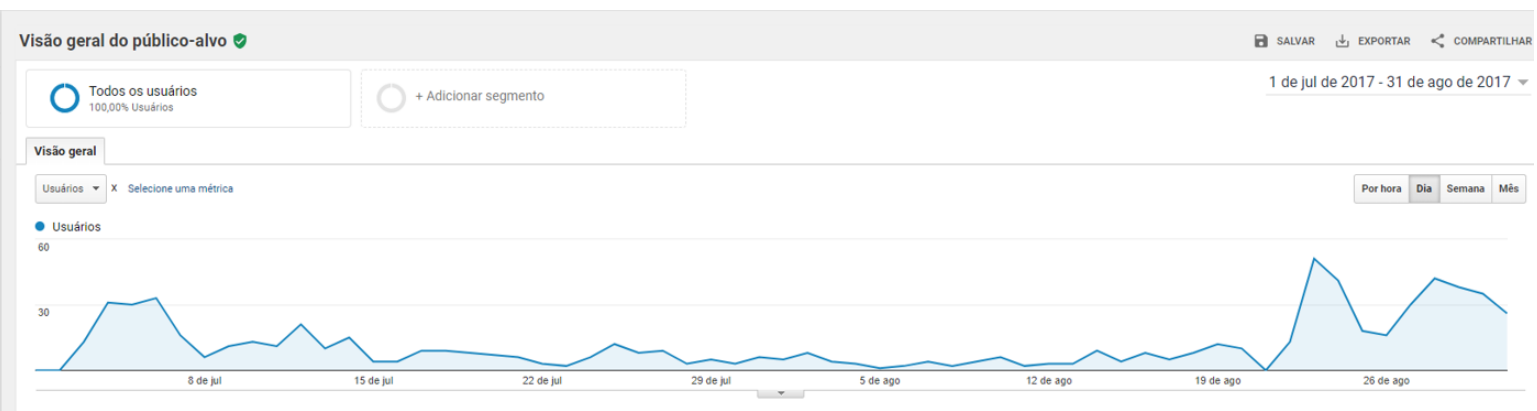

Fonte: Google Analytics

A partir dos dados fornecidos sobre as mídias utilizadas para acesso (Figura 6), percebese que a maioria das pessoas que acessou o recurso educacional chegou a ele por meio do acesso direto disponibilizado no curso.

Os dados também mostram que houve quem acessasse o recurso por meio dos links de compartilhamento do Facebook. Isso nos mostra que as ferramentas de compartilhamento em redes sociais são de fato utilizadas e podem servir para atrair 
usuários de fora do curso.

Outra observação interessante a partir desse dado vem do fato de que uma parte daqueles que acessaram via Facebook vieram, em sua origem, da versão mobile da rede social.

Isso ressalta a importância de pensar em recursos educacionais que sejam responsivos e, desta forma, possam ser visualizados tanto via computadores quanto via dispositivos móveis.

Figura 6. Origem/mídia dos usuários do recurso

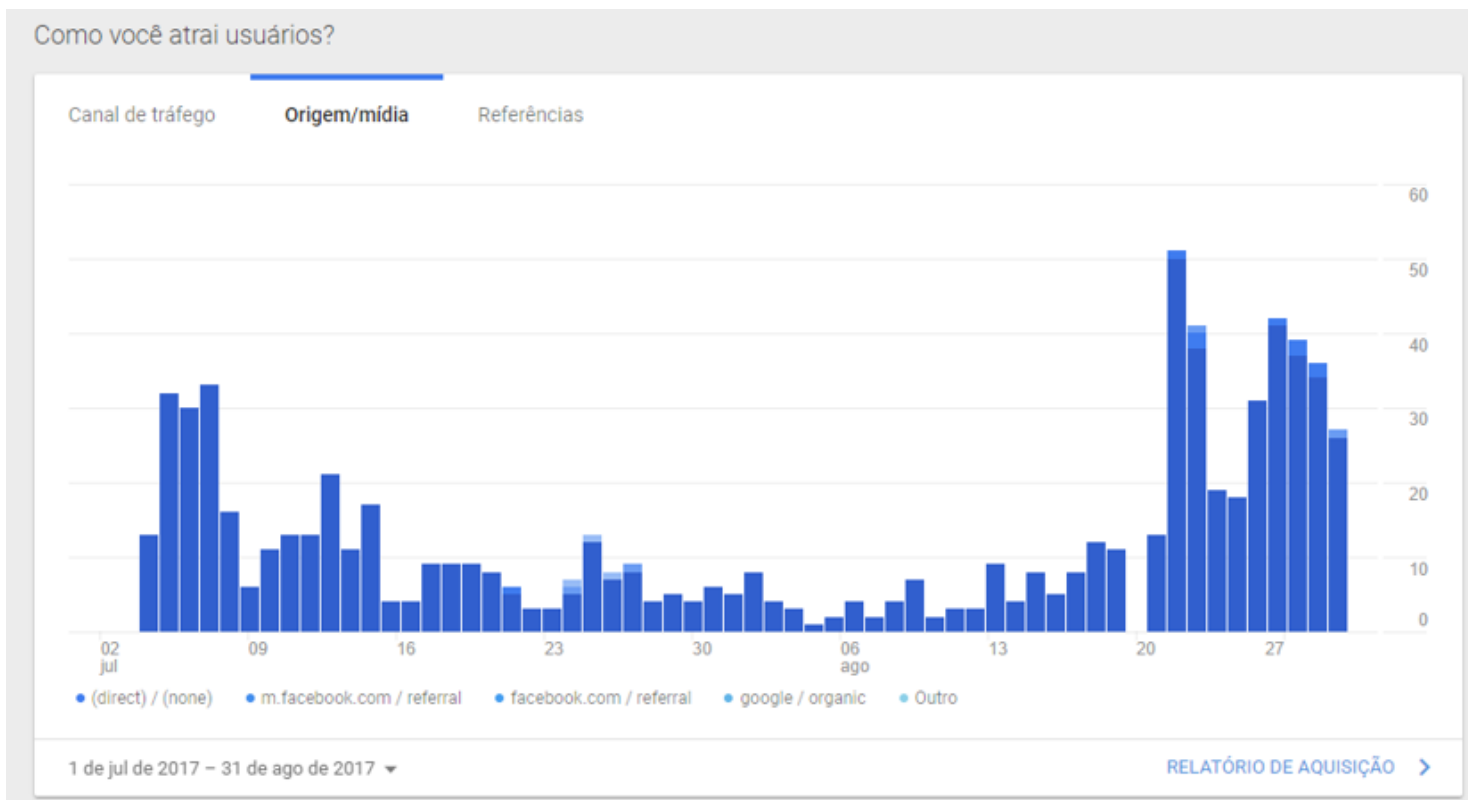

Fonte: Google Analytics

O gráfico apresentado na Figura 7 reforça a importância de planejar o desenvolvimento do recurso educacional, tanto para acesso via computador pessoal quanto via smartphones e tablets.

As sessões por dispositivos registram que $86,1 \%$ delas ocorreram via computador; $11,9 \%$ via celular e $2 \%$ via tablet. Os dados quantitativos aqui apresentados elucidam uma preocupação que parece estar ganhando cada vez mais espaço na produção de REA: a importância da responsividade, da acessibilidade e do compartilhamento.

Considerando que muitas pessoas estão trocando os computadores pelos dispositivos móveis para acessar conteúdos digitais, é preciso que esses conteúdos possam ser acessados corretamente de qualquer dispositivo, seja ele mobile ou não, e por qualquer 
pessoa, com ou sem deficiência.

Figura 7. Sessões por dispositivo

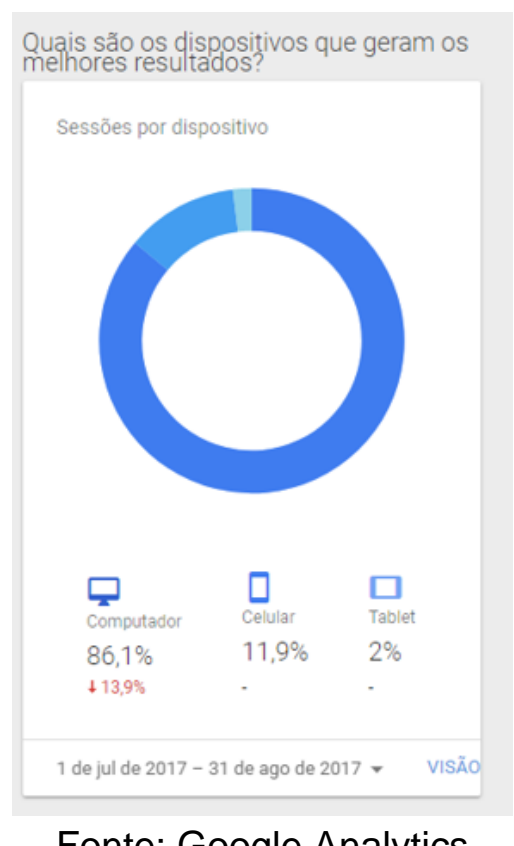

Fonte: Google Analytics

Além disso, facilitar o compartilhamento desses objetos por meio de botões específicos é um forma de fazer com que os REA cheguem a um público maior do que apenas aqueles a quem inicialmente foram destinados.

\section{Considerações finais}

O presente trabalho teve como objetivo analisar a produção e o uso do REA "Qual o meu pensamento sobre a deficiência", utilizado no contexto do curso "Direitos da Pessoa com Deficiência: Diversidade Humana e Igualdade", ofertado pela UNIVESP em parceria com a Secretaria de Estado dos Direitos da Pessoa com Deficiência. A respeito do processo de produção, ficou demonstrada a materialização dos princípios da instituição no recurso, sempre seguindo as etapas já consolidadas anteriormente: brainstorming, metáfora e prototipação.

O mesmo processo produtivo permitiu a implementação de iniciativas de acessibilidade no material, como audiodescrição e navegação por meio do uso do teclado. Em termos do uso do REA, quantitativamente foi possível verificar que, embora uma pequena parcela dos alunos tenha postado no fórum suas impressões a respeito do recurso, foram registrados picos de acesso ao início e ao fim do curso, em geral ocorridos por meio do link direto e partindo do computador.

No entanto, há evidências de que parcela representativa dos usuários utiliza dispositivos 
móveis e chega ao recurso por meio do compartilhamento de links em redes sociais, incluindo em sua versão mobile. Assim, fica demonstrada a importância de se pensar em responsividade, acessibilidade e possibilidades de compartilhamento na criação de REA.

Mais do que isso: fica o registro para que pesquisas na área também dediquem-se a levantar possibilidades de acessibilidade para recursos de aprendizagem adaptáveis para celulares, uma vez que a acessibilidade e a interação proporcionadas pelos computadores é diferente daquela viável em dispositivos móveis. Estratégias como "mobile first" ou outras semelhantes podem ser testadas para verificar sua eficácia com relação à acessibilidade, já que o público que dela necessita é representativo e não pode ficar fora das iniciativas de educação.

\section{Referências}

ANDRADE, M. M. Introdução à metodologia do trabalho científico. 10. ed. São Paulo: Atlas, 2010.

FRANCO, E. P. C.; SILVA, M. C. C. C. Audiodescrição: breve passeio histórico. In: MOTTA, L. M. V. M.; ROMEU FILHO, P. Audiodescrição: transformando imagens em palavras. São Paulo: Secretaria dos Direitos da Pessoa com Deficiência do Estado de São Paulo, 2010. p. 23-42.

GARA, E. B. M.; et al. O processo de criação de REA: um relato de caso. In: CONGRESSO INTERNACIONAL ABED DE EDUCAÇÃO A DISTÂNCIA, 2016. Águas de Lindoia, Anais... São Paulo: ABED, 2016. Disponível em: <http://www.abed.org.br/congresso2016/trabalhos/86.pdf>. Acesso em: 23 abr. 2018.

LEAL FERREIRA, S. B.; NUNES, R. R. e-Usabilidade. Rio de Janeiro: LTC, 2008.

OLIVEIRA, É. T.; et. al. Acessibilidade em vídeos: um estudo em disciplinas de um curso de especialização em educação inclusiva. Educação, Formação \& Tecnologias, v. 9, n. $1, \quad$ p. 2016 58-71, Disponível em: <http://eft.educom.pt/index.php/eft/article/view/515/239>. Acesso em: 8 abr. 2018.

PRETTO, N. L. Professores autores em rede. In: SANTANA, B.; ROSSINI, C.; PRETTO, N. L. (Orgs.). Recursos Educacionais Abertos: práticas colaborativas políticas públicas. Salvador: Edufba; São Paulo: Casa da Cultura Digital, 2012. p. 91-108. 